\title{
Inhibition of microRNA-383 promotes apoptosis of human colon cancer cells by upregulation of caspase-2 gene expression
}

\author{
Jianfeng $\mathrm{Gu}^{1,2}$, Wei $\mathrm{Fu}^{3}$, Yang Zong ${ }^{2}$, Qiao Chen $^{2}$, Xiaojin Zhang ${ }^{2}$, Jianqing \\ Meng $^{2}$, Haixin Qian ${ }^{1 *}$ \\ ${ }^{1}$ Department of General Surgery, The First Affiliated Hospital of Soochow University, Suzhou, 215006, ${ }^{2}$ Department of General \\ Surgery, Changshu No. 1 People's Hospital Affiliated to Soochow University, Changshu, 215500, ${ }^{3}$ Department of Oncology, \\ Changshu No. 1 People's Hospital Affiliated to Soochow University, Changshu, 215500, Jiangsu, China
}

*For correspondence: Email: HLanettelahey@yahoo.com; Tel/Fax: 0086-0512-65223637

Sent for review: 4 July 2017

Revised accepted: 24 October 2017

\begin{abstract}
Purpose: To investigate microRNA-383 (miR-383) as a therapeutic target for the management of colon cancer.

Methods: Total RNA was isolated using RNeasy RNA isolation kit according to the manufacturer's instructions. cDNA was synthesized using RevertAid cDNA synthesis kit. Expression analysis was carried out by quantitative real-time polymerase chain reaction (RT-PCR). Cell proliferation was examined using CellTiter 96 AQueous One Solution Cell Proliferation Assay system, while apoptosis was detected by 4',6-diamidino-2-phenylindole (DAPI) and annexin V/PI double staining followed by flow cytometry. The miR-383 target was delimited using TargetScan software. Protein expression analysis was carried out by western blotting.

Results: The results indicate that miR-383 was highly expressed in colon cancer cells. Down-regulation of miR-383 inhibited cancer cell proliferation, and promoted apoptosis and cell cycle arrest. Furthermore, in silico analysis revealed caspase-2 gene to be the downstream target of miR-383, a finding that was further confirmed by western blotting.

Conclusion: The results reveal that miR-383 may be an important target to tackle the increasing incidence of colon cancer. Thus, drugs that target miR-383 and inhibit its expression can potentially be developed for the treatment of colon cancer.
\end{abstract}

Keywords: MicroRNA, Colon cancer, Cell proliferation, Apoptosis, Protein expression

\begin{abstract}
This is an Open Access article that uses a funding model which does not charge readers or their institutions for access and distributed under the terms of the Creative Commons Attribution License (http://creativecommons.org/licenses/by/4.0) and the Budapest Open Access Initiative (http://www.budapestopenaccessinitiative.org/read), which permit unrestricted use, distribution, and reproduction in any medium, provided the original work is properly credited.
\end{abstract}

Tropical Journal of Pharmaceutical Research is indexed by Science Citation Index (SciSearch), Scopus, International Pharmaceutical Abstract, Chemical Abstracts, Embase, Index Copernicus, EBSCO, African Index Medicus, JournalSeek, Journal Citation Reports/Science Edition, Directory of Open Access Journals (DOAJ), African Journal Online, Bioline International, Open-J-Gate and Pharmacy Abstracts

\section{INTRODUCTION}

Among the gastrointestinal cancers, colon cancer is one of most prevalent types [1]. Owing to the drastic alterations in human life styles, the incidence of cancer has significantly increased globally. Studies have reported that colon cancer is the second major reason for cancer-related deaths among all malignant tumors [2]. Currently, the treatment of colon cancer involves surgery, followed by chemotherapy. However, the prognosis for colon cancer is very poor, and the 
mortality rate is high [3]. Therefore, there is an urgent need to develop novel treatment strategies or explore novel targets to limit the increasing incidence of colon cancer. MicroRNAs (miRNAs) include a large family of small noncoding RNAs that are involved in the inhibition of protein synthesis by binding to different sites in the 3'-untranslated region (3'UTR) of target genes. Therefore miRNAs exhibit remarkable biological significance and play a role in diverse cellular process $[4,5]$.

Among several human miRNAs associated with cancers, hsa-microRNA-383-5p (miR-383) has been reported to be principally upregulated. Thus, it has been reported to promote tumor progression in several cancers, including, but not limited to, gastric cancer and glioma [6,7].

In the present study, the expression of miR-383 was determined in different colon cancer cell lines, and miR-383 was explored as a potential therapeutic target for the treatment of colon cancer.

\section{EXPERIMENTAL}

\section{Colon cancer cell lines and culture conditions}

All the chemicals and reagents were obtained from Sigma-Aldrich Co. (St. Louis, MO, USA) unless otherwise mentioned. Primary and secondary antibodies were purchased from Santa Cruz Biotechnology Inc. (Santa Cruz, CA, USA). Six human colon cancer cell lines, CCL233, CL-188, CL-231, HTB-37, HTB-39, and CRL-7280, and one normal cell line, CRL-1459, were purchased from Type Culture Collection of Chinese Academy of Sciences (Shanghai, China). Cell culture was carried in RPMI-1640 medium containing $10 \%$ fetal bovine serum, appropriate antibiotics, with maintenance in a humidified atmosphere containing $5 \% \mathrm{CO}_{2}$. All of the reagents were procured from Hyclone.

\section{RNA isolation, cDNA synthesis, and expression analysis}

Total RNA was isolated using the RNeasy kit according to the manufacturer's instructions. Quality check of the RNA samples was performed by measuring the absorbance using a NanoDrop ${ }^{\circledR} \quad$ ND-1000 spectrophotometer (NanoDrop Technologies), calculating the 260 $\mathrm{nm} / 280 \mathrm{~nm}$ ratio and separation on $1 \%$ agarose gels. DNA contamination was removed by DNase I (Fermentas) treatment. cDNA was synthesized using the RevertAid cDNA synthesis kit (Fermentas) according to the manufacturer's protocol.
The relative quantification method $(\Delta \Delta-C T)$ was used to determine the quantitative variation among the replicates examined. $\beta$-Actin was used as a positive control to normalize the data.

\section{Inhibition of miR-383 in colon cancer cells}

The inhibitor of human miR-383 (MiR383-In, 107 units $/ \mathrm{mL}$ ) and its non-specific miRNA lentivirus (MiR-C, 107 units $/ \mathrm{mL}$ ) were obtained from RiboBio (RiboBio, China). CL-188 cells were incubated with lentiviral particles $(10 \mathrm{~mL} / 1000$ cells; multiplicity of infection $=10-15)$ and polybrene $(8 \mathrm{mg} / \mathrm{mL})$ for $48 \mathrm{~h}$. Thereafter, the media were replaced, and CL-188 cells were incubated for another 3-7 days for stabile transduction. The cells were then passaged and preserved in vitro for further analysis.

\section{Proliferation assay}

Oral cancer CL-188, microRNA-inhibited CL-188 cancer cells, and normal CRL-1459 were separately seeded into 96-well plates, with each well containing approximately 5,000 cells and the cells permitted to grow for 5 days. Thereafter, cell proliferation was examined using the cell proliferation assay kit (Promega USA) according to the manufacturer's guidelines. At every 24-h interval, $15 \mathrm{~mL}$ of MTT solution was administrated to each well for $2 \mathrm{~h}$ at $37^{\circ} \mathrm{C}$. The absorbance was recorded at $570 \mathrm{~nm}$ using a spectrophotometer.

\section{Apoptosis assay}

Colon cancer CL-188, microRNA-inhibited CL188 cancer cells, and normal CRL-1459 cells were separately seeded at density of $2 \times 10^{5}$ cells/well in 6-well plates and were treated with different concentrations of cisplatin and then were incubated for 24 h. Apoptosis was examined by incubating the cells in 6-well plates for $24 \mathrm{~h}$ with DAPI.

The cells were then washed with PBS, fixed in 10 $\%$ formaldehyde, followed by another wash with PBS. The DAPI-stained cells were then examined by fluorescence microscopy. For annexin V/PI staining, a similar procedure to that of DAPI was followed except the cells were treated with annexin V/PI and were investigated by flow cytometry.

\section{Identification of the miR-383 target}

To gain insight into the potential target of miR383 , the TargetScan search program was used. 


\section{Western blotting}

Total protein from the cancer cells was isolated using RIPA lysis buffer. The proteins were quantified using the BSA protein assay kit, and equal protein extracts from each group were resolved by sodium dodecyl sulfatepolyacrylamide gel electrophoresis, followed by transfer to a polyvinylidene fluoride membrane. Next, the membrane was blocked with $5 \%$ nonfat milk and incubated at room temperature for 1 h. Thereafter, the membranes were incubated with the primary antibody at $4{ }^{\circ} \mathrm{C}$ overnight, followed by washing in washing buffer and incubation with the secondary antibody for $1 \mathrm{~h}$. The protein bands of interest were visualized using the ECL Advanced Western Blot Detection Kit.

\section{Statistical analysis}

The experiments were repeated three times, and the values were expressed as means \pm SD. GraphPad 7 software was used for statistical analysis. The values were considered significant at ${ }^{*} p<0.01,{ }^{* *} p<0.001$, and ${ }^{* * *} p<0.0001$, as appropriate.

\section{RESULTS}

\section{miR-383 is upregulated in colon cancer cell lines}

The expression of miR-383 was determined in six different oral cancer cell lines (CCL-233, CL188, CL-231, HTB-37, HTB-39, CRL-7280) and one normal cell line CRL-1459 (Figure 1) by quantitative RT-PCR analysis. The results of this study revealed that the expression of miR-383 was considerably upregulated in all the oral cancer cell lines compared with that in the control. These results of expression analysis indicated that miR-383 may prove to be an important therapeutic target.

\section{Inhibition of miR-383 promotes growth inhibition}

To understand the role of miR-383 in colon cancer, its expression was inhibited in colon cancer CL-188 cells through lentiviral transduction. The results indicated that the inhibition of miR-383 caused significant inhibition of the growth of colon cancer cells as evident from the proliferation assay (Figure 2). These results suggest that miR-383 is required for the proliferation of colon cancer cells.

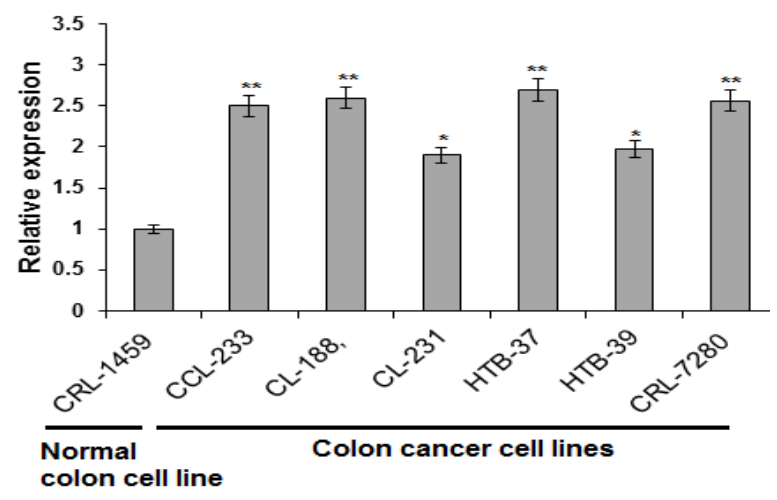

Figure 1: Expression of miR-383 in normal colon and colon cancer cell lines. The experiments were carried out in triplicate and were expressed as means \pm SD. The values were considered significant at ${ }^{*} p<0.01$, ${ }^{* *} p<0.001$, and ${ }^{* *} p<0.0001$

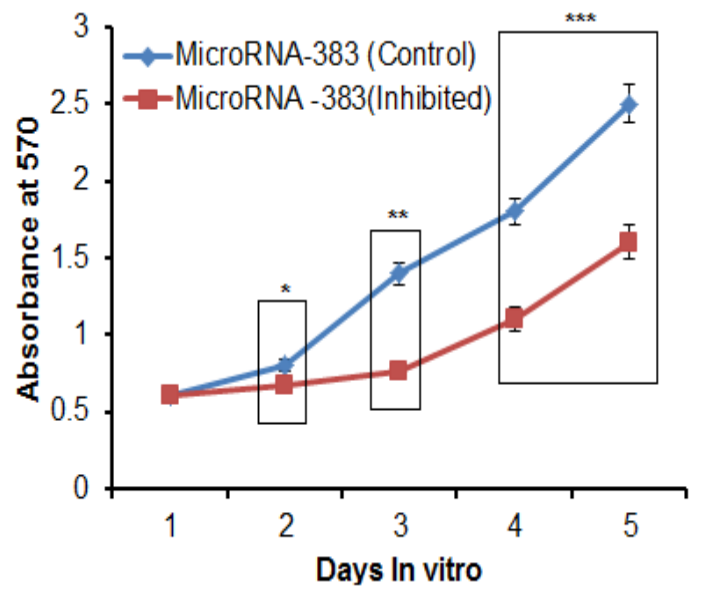

Figure 2: Proliferation of control colon cancer CL-188 cells with normal microRNA-383 expression and CL188 cells with inhibited microRNA-383 expression. The experiments were carried out in triplicate and were expressed as means \pm SD. The values were considered significant at ${ }^{*} p<0.01,{ }^{* *} p<0.001$, and ${ }^{* * *} p<0.0001$

\section{Inhibition of miR-383 promotes apoptosis}

The results indicated that the inhibition of miR383 results in the inhibition of cell growth. Therefore, to ascertain whether the antiproliferative effects are due to the induction of apoptosis, DAPI staining was carried out. Interestingly, the results indicated that the inhibition of miR-383 in colon cancer CL-188 cells led to the triggering of apoptosis (Figure 3). Furthermore, the apoptotic cell populations were examined by annexin V/PI double staining. The results showed that the apoptotic cell distribution was $39.6 \%$ in miRNA-inhibited cells compared with $2.61 \%$ in control CL-188 cells (Figure 4).

\section{Inhibition of miR-383 induces cell cycle arrest}

The cell cycle phase distribution in miR-383 silenced and control CL-188 colon cancer cells 
was further determined. The results suggested that miR-383 inhibition promotes G2/M cell cycle arrest as evident by the accumulation of a higher number of CL-188 oral cancers in the G2 phase of the cell cycle (Figure 5).
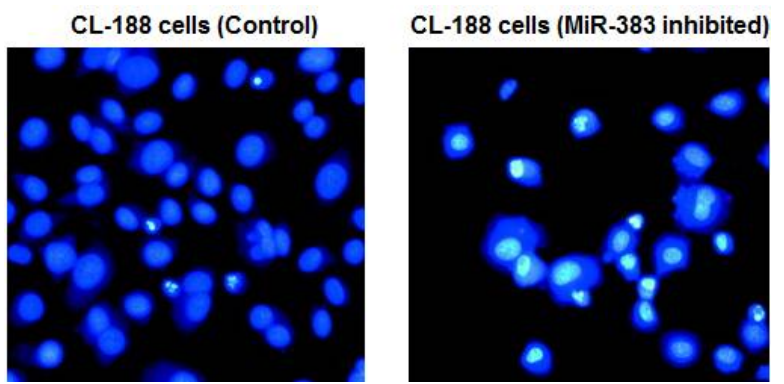

Figure 3: Detection of apoptosis by DAPI staining in control colon cancer CL-188 cells with normal miR-383 expression and CL-188 cells with inhibited miR-383 expression. The experiments were carried out in triplicate
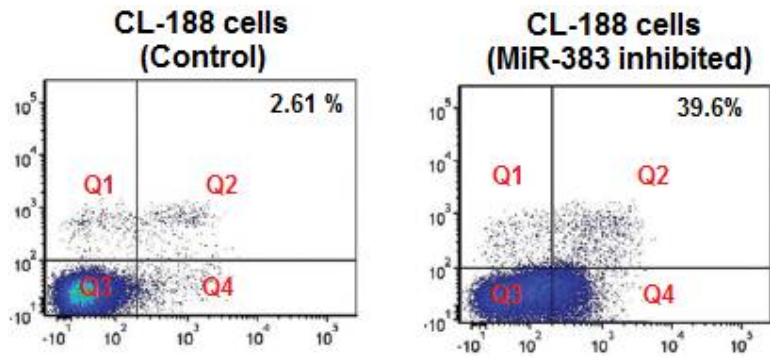

Figure 4: Estimation of the apoptotic cell distribution by annexin V/PI staining in control colon cancer CL188 cells with normal miR-383 expression and CL-188 cells with inhibited miR-383 expression. The experiments were carried out in triplicate
CL-188 cells (Control)

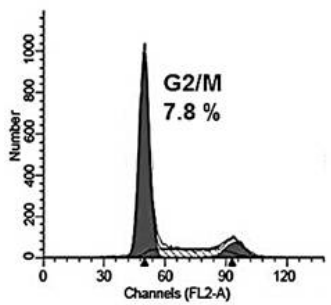

CL-188 cells (MiR-383 inhibited)

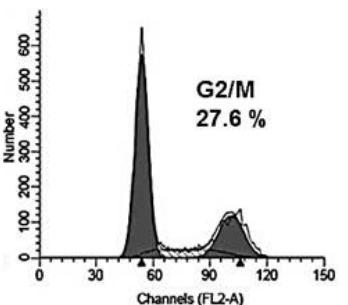

Figure 5: Cell cycle analysis of control colon cancer CL-188 cells with normal miR-383 expression and CL188 cells with inhibited miR-383 expression. The experiments were carried out in triplicate

\section{miR-383 targets the caspase 2 gene}

To identify the downstream target gene of miR383, the target scan (www.targetscan.org) server was used. CASP2 was observed to be a potential target gene of miR-383. The 3'-UTR DNA segment of CASP2 was found to be complimentary to the binding of miR-383 (Fig. $5 A)$. Next, to further confirm that CASP2 is the actual target of miR-383, the expression of the CASP2 gene in colon cancer CL-188 and miRNA-inhibited CL-188 cancer cells was examined by western blotting. The results revealed that miR-383 inhibition considerably enhanced CASP-2 gene expression in CL-188 cells, further validating that the CASP-2 gene is the potential target of miR-383 in colon cancer cells.
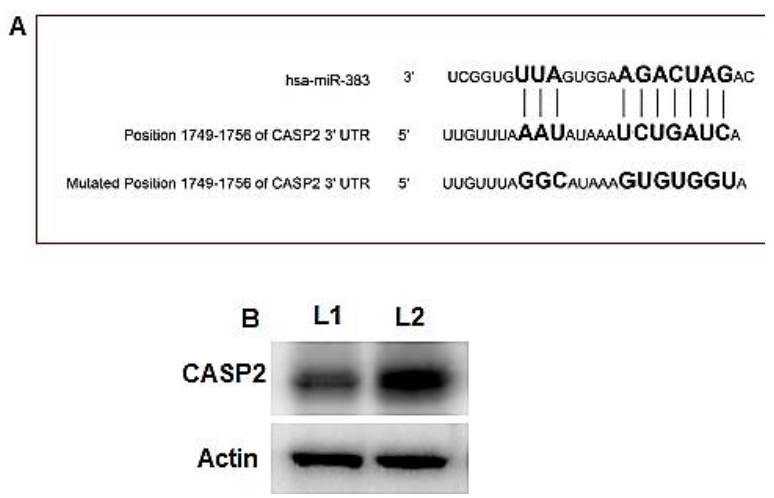

Figure 6: The miR-383 target CASP-2 gene. (A) TargetScan revealed the CASP-2 gene as the potential target of miR-383. (B) Expression of CASP-2 protein in control colon cancer CL-188 cells with normal miR-383 expression (L1) and in CL-188 cells with inhibited miR-383 expression (L2). The experiments were carried out in triplicate

\section{DISCUSSION}

It is now well established in the literature that miRNAs play vital roles in human cancer development and its progression through different stages [8]. The expression of miRNAs may be either enhanced or suppressed depending on whether they promote or suppress the tumorigenesis and progression of cancers. Recently, miRNAs have been considered important therapeutic targets for the management of several types of cancers [9]. miR-383 has been reported to play vital roles in human cancers such as ovarian cancer [10]. However, the exact role and underlying mechanism of miRNA-383 in the development of cancer progression have not been thoroughly studied.

In the present study, the expression of miR-383 was investigated in six different colon cancer cell lines and one normal cell line. The results of this study revealed that the expression of miR-383 was highly upregulated in all the colon cancer cell lines. The results of this study agree with previous study data wherein the expression of miR-383 was observed to be highly enhanced in several cancers. For instance, Liu et al reported that the expression of miR-383 was highly enhanced in ovarian cancer cells [10]. More 
interestingly, some studies have even reported that the expression of miR-383 is down-regulated in cancers like gastric cancer and glioma [6,7]. These results, as well as those of previous studies, clearly indicate that miR-383 may be an important therapeutic target.

To confirm the role of miR-383 in colon cancer, silencing of microRNA expression in CL-188 colon cancer cells was performed by lentiviral transduction. The inhibition of miR-131 was demonstrated to inhibit the cell proliferation of CL-188 cells compared with that in the control. Furthermore, to gain insights into the mechanism by which miR-383 promotes the inhibition of cell proliferation, DAPI staining was carried out. The results indicated that the inhibition of miR-383 triggered apoptosis in CL-188 cells. The latter finding was further confirmed by annexin V/PI staining, which revealed that miR-383 caused 39 $\%$ of apoptosis compared with $3.4 \%$ in the control. Apoptosis is an important mechanism by which cancerous cells are removed from the body. Several anticancer agents have been reported to exhibit anticancer activities via the induction of apoptosis. In addition, apoptosis is an important mechanism to avoid the development of drug resistance [11]. Moreover, besides apoptosis, cell cycle arrest is considered an important mechanism by which anticancer agents exert their effects [12].

The results of the present study clearly showed that the inhibition of $\mathrm{miR}$, leading to G2/M cell cycle arrest in colon cancer CL-188 cells, was quite evident from the increased number of colon cancer cells in the G2 phase of the cell cycle. Next, the online software TargetScan was used to delimit the potential target of miR-383. The results showed CASP-2, a member of cysteine protease family, was the downstream target gene of miR-383. Recent studies have demonstrated that CASP-2 protein triggers cell death in human cancer cells, possibly via the suppression of fatty acid synthase [13]. To further confirm the involvement of CASP-2 in miR-383-prompted cell death, we investigated the expression of CASP-2 in CL-188 cells with silenced miR-383. The results indicated that the expression of CASP-2 was highly enhanced in these cells, confirming the involvement of CASP-2 in microRNAtriggered cell death in colon cancer cells.

\section{CONCLUSION}

The findings of this study indicate that miR-383 may be an important target to stem the increasing incidence of colon cancer. Thus, drugs that target miR-383 and inhibit its expression can potentially be developed for the treatment of colon cancer.

\section{DECLARATIONS}

\section{Conflict of Interest}

No conflict of interest is associated with this work.

\section{Author contributions}

We declare that this work was done by the authors named in this article and all liabilities pertaining to claims relating to the content of this article will be borne by the authors. Jianfeng $\mathrm{Gu}$ and $\mathrm{Fu}$ Wei carried out the experiments under the supervision of Haixin qian. Yang Zong, contributed equally to the work. Qiao Chen offered assistance in preparing this manuscript. Xiaojin Zhang did statistical analysis. Jianqing Meng is involved in interpreting the data.

\section{REFERENCES}

1. Hong $M Y$, Seeram $N P$, Zhang $Y$, Heber D. Anticancer effects of Chinese red yeast rice versus monacolin $K$ alone on colon cancer cells. JNutrBiochem 2008; 19: 448-458.

2. Ricci-Vitiani L, Lombardi DG, Pilozzi E, Biffoni M, Todaro $M$, Peschle $C$, De Maria $R$. Identification and expansion of human colon-cancer-initiating cells. Nature 2007; 445: 111-115

3. Watanabe T, Wu TT, Catalano PJ, Ueki T, Satriano R, Haller DG, Benson AB, Hamilton SR. Molecular predictors of survival after adjuvant chemotherapy for colon cancer. N Engl J Med 2001; 344: 1196-1206.

4. Farazi TA, Hoell Jl, Morozov P, Tuschl T. MicroRNAs in human cancer. InMicroRNA Cancer Regulation. Springer Netherlands. 2013; pp 1-20

5. Calin GA, Croce CM. MicroRNA-cancer connection: the beginning of a new tale. Cancer Res 2006; 66: 73907294.

6. He Z, Cen D, Luo X, Li D, Li P, Liang L, Meng Z. Downregulation of miR-383 promotes glioma cell invasion by targeting insulin-like growth factor 1 receptor. MedOncol 2013; 30: 557-561.

7. Luo $H$, Zhang $H$, Zhang $Z$, Zhang $X$, Ning B, Guo J, Nie $N$, Liu B, Wu X. Down-regulated miR-9 and miR-433 in human gastric carcinoma. J ExpClinCancer Res2009; 28: 87-91.

8. Calin GA, Croce CM. MicroRNA signatures in human cancers. Nat Rev Cancer2006; 6: 857-866.

9. Esquela-Kerscher A, Slack FJ. Oncomirs-microRNAs with a role in cancer. Nat Rev Cancer 2006; 6: 259-269.

10. Yin M, Lü M, Yao G, Tian H, Lian J, Liu L, Liang M, Wang $Y$, Sun $F$. Transactivation of microRNA-383 by steroidogenic factor-1 promotes estradiol release from 
mouse ovarian granulosa cells by targeting RBMS1. MolEndocrino 2012; 26: 1129-1143.

11. Brown JM, Attardi LD. The role of apoptosis in cancer development and treatment response. Nat Rev Cancer 2005; 5:231-237.
12. Hartwell LH, Kastan MB. Cell cycle control and cancer. Science 1994; 266: 1821-1826.

13. Lassus $P$, Opitz-Araya $X$, Lazebnik Y. Requirement for caspase-2 in stress-induced apoptosis before mitochondrial permeabilization. Science 2002; 297: 1352-1354. 